\title{
The value of time and external benefits in bicycle appraisal
}

Maria Börjesson and Jonas Eliasson

The self-archived postprint version of this journal article is available at Linköping University Institutional Repository (DiVA):

http://urn.kb.se/resolve?urn=urn:nbn:se:liu:diva-181310

N.B.: When citing this work, cite the original publication.

Börjesson, M., Eliasson, J., (2012), The value of time and external benefits in bicycle appraisal, Transportation Research Part A, 46(4), 673-683. https://doi.org/10.1016/j.tra.2012.01.006

Original publication available at:

https://doi.org/10.1016/j.tra.2012.01.006

Copyright: Elsevier

http://www.elsevier.com/

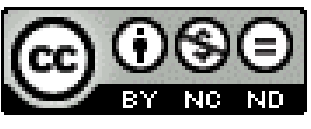




\title{
The value of time and external benefits in bicycle appraisal
}

\author{
Maria Börjesson \\ Jonas Eliasson \\ Published as: Börjesson, M. and Eliasson, J. (2012) The value of time and external benefits in \\ bicycle appraisal. Transportation Research A 46(4), 673-683. doi:10.1016/j.tra.2012.01.006.
}

\begin{abstract}
We estimate the value of time savings, different cycling environments and additional benefits in cost-benefit analysis of cycling investments. Cyclists' value of travel time savings turns out to be high, considerably higher than the value of time savings on alternative modes. Cyclists also value other improvements highly, such as separated bicycle lanes. As to additional benefits of cycling improvements in the form of health and reduced car traffic, our results do not support the notion that these will be a significant part in a cost-benefit analysis. Bicyclists seem to take health largely into account when making their travel choices, implying that it would be double-counting to add total health benefits to the analysis once the consumer surplus has been correctly calculated. As to reductions in car traffic, our results indicate that the cross-elasticity between car and cycle is low, and hence benefits from traffic reductions will be small. However, the valuations of improved cycling speeds and comfort are so high that it seems likely that improvements for cyclists are cost-effective compared to many other types of investments, without having to invoke second-order, indirect effects. In other words, our results suggest that bicycle should be viewed as a competitive mode of travel and not primarily as a means to achieve improved health or reduced car traffic.
\end{abstract}




\section{Introduction}

The bicycle as a mode of transport has received increasing attention in recent years. There also seems to be an increasing interest among planners to improve the bicycle transport system. For example, the EU commission's Green Paper “Towards a new culture for urban mobility" (European Commission, 2007) states that "More attention should be paid to the development of adequate [bicycle] infrastructure". Bicycle is often an efficient mode of transport in terms of speed and cost for the traveler, and also in terms of urban space. Still, bicycle investments are seldom evaluated using the standard cost-benefit analysis (CBA) that is used to evaluate road and rail investments. One possible reason is that the methodology is less developed for bicycle trips. Another possible reason is the implicit perception that cyclists have so low willingness to pay for time savings or other improvements that bicycle investments need to be motivated by "additional" benefits in the form of increased health, environmental effects or reduced road congestion. Indeed, there seems to be great expectations that such benefits will constitute a major part of the benefits in bicycle CBA.

Hence, there seems to be a growing need for reliable CBAs for bicycle investments and bicycle-related policy measures. This paper contributes to the development of better bicycle CBA methodology. The main purpose of the study is to estimate bicyclists' value of travel time savings, as well as valuations of a number of other improvements: bicycle paths, bicycle parking, and shorter waiting times at signaled intersections. A secondary purpose of the study is to assess the magnitude of "additional benefits" of improvements that increase cycling, in particular health effects and (to a less extent) benefits from reduced car traffic. The results are based on a stated choice survey carried out among cyclists in Stockholm during 2008.

Time savings usually constitute the major part of the benefits of transport investments. For example, $90 \%$ of the benefits in the Swedish Transport Investment Plan 2010-2021 consist of reduced transport times and transport costs (Eliasson \& Lundberg, 2011). Obviously, one needs reliable estimates of bicyclists' values of time to be able to evaluate benefits of improvements for cyclists. There are only a few previous studies devoted to cyclists' value of time. Wardman et al. (2007) employ stated-preference (SP) and revealed-preference (RP) data to estimate a mode choice model for commuting trips, with a special focus on the bicycle mode. The model gives an implicit RP-based value of time of $18.17 € /$ hour $^{1}$ for cyclists, almost three times the value of time for the "alternative" (second-best) mode. Stangeby (1997) finds a value of time of $10.17 € / \mathrm{h}^{2}$ for cyclists in an SP study that resembles the present one.

Employing SP data, Wardman et al. (2007) and Hopkinson and Wardman (1996) find that cycle facilities which reduce risk are highly valued. For example, the latter study estimates the value of separate paths for cyclists to $1.60 € /$ hour relative to no cycling facilities. Analyzing the use of bicycle within different municipalities in the Netherlands, Rietveld and Daniels (2004) also conclude that physical aspects such as the number of stops and the safety of cyclists influence

\footnotetext{
${ }^{1}$ Using the exchange rate $1.15 £ / €$ and adjusting nominal 1999 valuations to nominal 2008 valuations by a factor 1.36 , based on $1.5 \%$ year inflation and $2 \%$ /year valuation increase due to income growth.

${ }^{2}$ Using the exchange rate $8.47 \mathrm{NOK} / €$ and adjusting nominal 1997 valuations to nominal 2008 valuations by a factor 1.46 .
} 
the generalized cost of cycling. Elvik (2000) discusses traffic safety in bicycle CBA in more detail.

Sælensminde (2004) and CBA practice in Nordic countries ((Krag, 2005); (Saari \& Metsäranta, 2005); (Swedish Environmental Protection Agency, 2005)) argue that health effects constitute a major additional benefit in bicycle CBA. However, it is not evident that health effects should be treated as an additional (or "external") benefit, even if there is a broad consensus that there are significant health benefits to be gained from cycling. The key issue is to what extent health benefits are internalized, i.e. to what extent people take health effects into consideration when choosing whether to cycle. If health effects are internalized, then health benefits will be included as consumer surplus in the CBA, and adding health effects to the CBA will be doublecounting. Since health benefits potentially constitute a significant part of total benefits $(60-70 \%$ in Sælensminde's case studies), it is important to try to estimate to what extent health benefits are already factored in by bicyclists when they choose their mode of transport. We try to assess this by analyzing complementary survey questions.

Obviously, awareness of health benefits may differ between cities, countries and contexts. Moreover, it is extremely difficult to know whether cyclists estimate effects on their health correctly, even if they are "aware" of the effect in principle: both over- and underestimations are possible. A central question is hence where the burden of proof lies, or in other words, whether the "null hypothesis" in lack of conclusive evidence is that cyclists do take effects on own health into account or that they do not. The classic standpoint in the economics literature is that own health is primarily an individual responsibility, a position motivated by the fundamental principle of consumer sovereignty. This standpoint has been challenged from various angles. A particularly relevant discussion is the literature on "sin taxes" (O'Donoghue \& Rabin, 2006), (O'Donoghue \& Rabin, 2003), where optimal policy rules are derived for situations where consumers do not have full information or self-control, and hence may act against their own best self-interest.

Another potential "additional benefit" of bicycle improvements is reductions of car traffic, resulting in reduced emissions and congestion. Whether this effect will be significant will depend on the cycle/car cross-elasticity. In principle, this cross-elasticity should be possible to obtain from transport demand models. Unfortunately, such models are usually not developed with a great deal of attention on the possibility to forecast bicycle effects, and hence, results from them need to be corroborated by other forms of direct evidence. Katz (1995) concludes that traditional forecasting modeling techniques are not treating a minority mode such as cycling as good as other modes. One exception is Ortúzar et al. (2000) who estimate a dedicated bicycle demand model, although based on SP data. Another exception mentioned earlier is Wardman et al. (2007) who estimate a mode choice model on combined RP and SP data, and thereby adjust the response scale to be appropriate for forecasting. As Rietveld and Daniels (2004) point out, it seems that the bicycle competes primarily with public transport.

In this paper, we study bicyclists in central Stockholm. Cycling is an increasingly important mode of transport in Stockholm, especially in the urban center. Roadside count data shows a steady increase beginning around 1990, with cycling volumes more than doubling in 20 years 
(City of Stockholm, 2009). In relative terms, the increase is particularly pronounced during wintertime. Cycling does not increase in other parts of Sweden, though, but seems to have a stable role in the transport system (National Travel Surveys 1997-2001 and 2006, own calculations). Börjesson and Eliasson (forthcoming) describe this rapid development on more detail and discuss possible reasons for it. Bicycle mode shares vary surprisingly much between countries. Perhaps even more surprisingly, there seems to be no apparent connection to climate conditions. Sweden and the other Nordic countries have high bicycle shares, despite relatively cold winters. The top seven European countries in terms of bicycle shares are the Nordic countries together with Germany, the Netherlands and Belgium - Sweden is number five on the list (Rietveld \& Daniel, 2004) (quoting the EU Energy and Transport). Ebert and Carstensen (forthcoming) discuss the historical development of a bicycle-oriented planning in Northern Europe.

The paper is organized as follows. Section 2 summarizes the theory of valuation of travel time, and formulates a number of expectations about how the value of cycling time may vary. Section 3 describes the survey and characteristics of the responding cyclists. Results are compared to the Stockholm County travel survey 2004/2006, to assess the representativity of the current sample with respect to bicyclists in the whole county. In section 4, results from the value of time study are presented. Section 5 is devoted to the discussion of "additional benefits", i.e. to what extent health and environmental benefits should be added to a bicycle CBA. Section 6 concludes.

\section{Theory of valuation of travel time}

The theory of the value of travel time is well developed. Becker (1965) seems to be the first to propose a general theory for the allocation of time and income. His framework was later refined by DeSerpa (1971) and Evans (1972). Jara-Díaz (2003) and Jara-Diaz \& Guevara (2003) extend the classic framework into a general time allocation and consumption framework. In short, the monetary valuation of a travel time saving consists of three components: the resource value of time (the utility that could be attained if the travel time was used for some other activity, also called the opportunity value), the direct utility of travel time (compared to some reference activity), and the marginal utility of money. Given this, the value of time can be written as:

$$
\text { value of time }=\frac{\text { resource value of time }- \text { direct utility of travel time }}{\text { marginal utility of money }}
$$

If a travel time saving can be converted into more working hours, the first part is equal to the wage rate (after tax), giving

$$
\text { value of time }=\text { wage rate }-\frac{\text { direct utility of travel time }}{\text { marginal utility of money }}
$$

Marginal utilities cannot be observed directly, but we may expect that they are affected by various observable characteristics of the trip and the traveller. The direct utility of travel time is 
affected by factors such as the comfort of the mode and the productivity or enjoyability of the trip. Further, it is measured in comparison to the utility of being at the origin or the destination, and hence it will be lower (and the value of time higher) on the way to an important meeting or on the way home late at night. The resource value of time should increase the less available time the traveller has in general. Hence, we may expect it to be higher for employed people and for parents of small children. The marginal utility of money can be expected to be related to the income of the traveller, and possibly his or her medium-term fixed costs such as the number of family dependants.

As to the value of time savings for bicycle trips, the fact it is comparatively onerous and unproductive to cycle means that one might expect value of cycling time should be higher than for other modes ceteris paribus, since this will decrease the "direct utility" of cycling time compared to other modes. Similarly, one may expect the value of time to be lower on a bicycle path than for street cycling. On the other hand, if cyclists take the positive health effects into account, this should decrease the value of cycling time, since the health effects is a positive "direct utility" of cycling time. It follows that we should expect time spent cycling to be valued lower than time spent waiting at a signaled intersection, since there is no health effect of waiting, and possibly less enjoyable than cycling as well.

Self-selection will cause the average value of time to be higher on faster and more expensive modes (and vice versa), since travellers with high resource value of time and low marginal utility of money will choose faster and more expensive modes, ceteris paribus. For trips where cycling is slower than using other modes, one may hence expect that cyclists have a lower resource value of time than people choosing other modes (again ceteris paribus). It follows that the "cross-mode value of time", i.e. the value of time a cyclist would have on an alternative mode, could be expected to be lower than the value of time of the travellers actually choosing the alternative mode. Whether this effect is noticeable would depend on the relative differences in travel time and travel cost between the bicycle and the alternative mode. Moreover, one may expect that cyclists' average value of time will tend to decrease with travel distance, since the relative speed advantage of motorized modes will be larger for long trips (for short trips, the bicycle is usually faster than public transport and often as fast as the car from door to door): the longer the distance, the larger the time advantage of motorized modes will be, and consequently the lower the resource value of time of a traveller has to be if he is to choose to travel by bicycle.

One may also expect that self-selection will mean that actual cyclists have a higher direct utility of cycling than travellers choosing other modes (again ceteris paribus), in addition to the difference in value of time between modes induced by self-selection due to different resource values of time. It follows that if some policy measure causes some travellers to start cycling, the value of time of the "new" cyclists is likely to be higher than that of the "existing" cyclists. The potential difference in value of time between "existing" and "new" travellers is a potential problem when evaluating the value of travel time improvements for any mode - it is not unique for bicycle improvements. It is a customary approximation in practical CBA to ignore this complication, and use the same value of time both for "new" and "existing" travellers on the mode that is improved. 


\section{Survey design and respondent characteristics}

\subsection{The survey}

The survey was carried out as a hand-out/mail-back survey among cyclists in Stockholm in August 2008. The survey was handed out to cyclists during peak hours (7-10 and 15-18) at signalized intersections in the city center and on the roads leading to the city center, together with prepaid response envelopes. Depending on their stated trip time, respondents were given different variants of the survey with different versions of the stated choice questions - one for journeys shorter than 30 minutes and one for longer journeys. The persons administrating the survey had uniforms from the National Road Administration to increase the legitimacy of the survey, increase response frequency and reduce selection bias.

1422 cyclists were approached, of which 180 (13\%) declined to participate. Only respondents older than 18 years, on a journey longer than 15 minutes and understanding Swedish were recruited. The restriction that the trip had to be longer than 15 minutes was necessary to ensure that the stated choice experiments, varying travel times and costs, were realistic. This eliminated a further 62 approached cyclists (4\%). Out of the remaining 1180 respondents, 756 (64\%) mailed back completed questionnaires. Adding declining and non-responding cyclists together, the total response rate becomes $56 \%$. Time and place of all approached cyclists were noted, but the response rate did not differ significantly between those.

Trip times were fairly uniformly distributed in the interval 15-60 minutes, with an average of 29 minutes. The average trip length was $7 \mathrm{~km} .90 \%$ of the respondents had access to a separated bicycle path on more than half of the trip. $86 \%$ of the trips in the sample were work trips, with a somewhat higher share during morning hours and a somewhat lower share in the afternoon. $92 \%$ of respondents were employed and $5 \%$ were students. The age distribution was fairly uniform in the interval $18-65$ years, with an average of 41 years. Hence, cycling is not confined to younger age groups, contrary to beliefs sometimes encountered. $60 \%$ of respondents were female. This is higher than the corresponding figure from the Stockholm County travel survey $2004 / 2006$, which is $46 \%$ (see Table 1) (selecting cycle trips made on weekdays starting or ending in the inner city). It is likely that this difference is due to higher response rate for women in the present study ${ }^{3}$. Neither trip lengths, nor trip times, travel purposes or the age distribution differed between genders.

\footnotetext{
${ }^{3}$ Cyclists were approached when only when stopping for red light at signalized intersections, and all cyclists stopping for red light were approached to avoid selection bias. Many cyclists stopped at the same time in the morning peak, so the administrators had to be quick. Some of them just stopped long enough for the survey administrators to put the survey in their backpacks. For this reason the survey administrators had difficulties to keep track of the gender of the cyclists receiving a questionnaire.
} 
The average income in the sample was $3100 \mathrm{EUR} / \mathrm{month}^{4}$, somewhat higher than the average income in the county of Stockholm, which is around $2600 \mathrm{EUR} / \mathrm{month}$. However, 2600 EUR/month is the average of all persons 20-64 years with any salary during 2007 - including all part-time and seasonal workers (e.g. students), implying that this figure is bound to be lower than the average wage of peak hour work trips an ordinary weekday.

\subsection{Representativeness of the sample}

The sample is not representative for all bicycle trips in Stockholm County (or Sweden). Work trips and peak-hour trips are oversampled; central Stockholm has more road congestion and better public transit supply than the rest of the county; the choice of sampling locations tended to oversample longer trips. Table 1 compares characteristics of the trips in the sample with trips from the Stockholm County travel survey. The first column describes all bicycle trips in the county, the second column describes bicycle trips made on weekdays starting or ending in the inner city (which is roughly comparable to the trips in our sample) and finally the sample of the current survey. Income, share of work trips and share of employed respondents are higher in our sample, since respondents were sampled during peak hours. In the estimation section we also evaluate the values of time at the average income of cyclists in the county, and reweight the sample in terms of purpose and employment status to the average Stockholm County cyclist using the Swedish Value of Time study. This can, of course, still only give an indication of the average bicycle value of time in the county.

Table 1: Characteristics of the sampled trips, compared to Stockholm County travel survey 2004/2006

\begin{tabular}{|l|c|c|c|}
\hline & $\begin{array}{l}\text { Stockholm } \\
\text { county }\end{array}$ & $\begin{array}{l}\text { Starting/ending } \\
\text { in the inner city }\end{array}$ & $\begin{array}{l}\text { Our } \\
\text { sample }\end{array}$ \\
\hline Journey purpose: to/from work & $54 \%$ & $70 \%$ & $86 \%$ \\
\hline Average trip length & 3.9 & 5.1 & 7 \\
\hline Average trip length, work trips only & 4.9 & 5.8 & 7.4 \\
\hline Average trip time & 18 & 22 & 29 \\
\hline Average trip time, work trips only & 19 & 21 & 29 \\
\hline Trips by females & $46 \%$ & $40 \%$ & $60 \%$ \\
\hline Trips by employed & $63 \%$ & $78 \%$ & $92 \%$ \\
\hline Average age & 38 & 38 & 41 \\
\hline Average income ${ }^{5}$ EUR/month & 2500 & 2600 & 3100 \\
\hline
\end{tabular}

Trip lengths and trip times are bound to be higher in our sample than in the county travel survey, since trips shorter than 15 minutes were excluded and since the probability to be included in a roadside survey is proportional to trip length while the travel survey sample individuals randomly. Valuations from roadside sampling are more relevant than individual sampling when evaluating transport investments: the sample should reflect the composition of trips on a representative link.

\footnotetext{
${ }^{4}$ We use the conversion rate $1 \mathrm{SEK}=0.1 €$ throughout this paper.

5 The travel survey refers to the years 2004 and 2006, so income levels are not directly comparable with our sample collected 2008
} 


\section{Valuations of time and travel characteristics}

The survey contained two stated choice experiments, comprising nine binary choices each. The first experiment was a choice between bicycle and the respondent's second-best mode, which turned out to be public transit for $87 \%$ of the respondents while the rest chose car. The alternatives differed in terms of travel time, travel cost and the share of the bicycle trip on a separated bicycle path. Approximately $15 \%$ of the sample had a monthly ticket for public transit. These were just asked to imagine that they paid for each trip in the exercise. Results showed that the value of time of this group did not differ significantly from other travelers'. We assume that respondents reporting car as the alternative mode $(13 \%)$ had access to car so that the travel cost in the survey refers only to marginal cost of driving/parking.

The second experiment was a choice between two alternative bicycle routes, differing in terms of travel times, number of signalized intersections, total waiting time at those intersections and whether there was a bicycle parking facility at the destination.

\subsection{Valuation of time savings and cycle paths}

A logit model was estimated with the following specification of the utility functions:

$$
\begin{aligned}
U_{c} & =\delta_{n}+\delta_{\text {age }}+\left[\beta_{0}^{\text {path }}+f_{\text {path }}\left(T_{0}\right)\right] t_{\text {path }}+\left[\beta_{0}^{\text {street }}+f_{\text {street }}\left(T_{0}\right)\right] t_{\text {street }} \\
U_{\text {alt }} & =\left[\beta_{0}^{\text {alt }}+f_{\text {alt }}\left(T_{0}\right)\right] t_{\text {alt }}+\left[\alpha_{1}+\alpha_{2} \log (I / \bar{I})\right] c
\end{aligned}
$$

where $t_{\text {street }}$ denotes the travel time on a street shared with car traffic, while $t_{\text {path }}$ denotes the travel time on a separate bicycle path. $t_{a l t}$ and $c$ are the travel time and the travel cost of the alternative travel mode. $I$ is the after tax income of the respondent and $\bar{I}$ is the mean after tax income in the sample. $\delta_{n}$ is a mode choice constant, taken to be normally distributed across individuals $n . \delta_{n}$ is constant for each individual, which controls for the panel effect arising from repeated (and hence correlated) choices from each respondent. $\delta_{a g e}$ is a dummy parameter applying to respondents older than 40 years. The mixed logit model is estimated with 2000 random draws.

It is a common finding that the value of time on motorized modes increases with travel time (Abrantes \& Wardman, 2011), (Börjesson, Fosgerau, \& Algers, 2012a), (Börjesson, Fosgerau, \& Algers, 2012b). The effect of the baseline travel time (the travel time stated by the respondents) on the time and cost parameters was therefore explored. The effect is captured by the functions $f_{\text {path }}\left(T_{0}\right), f_{\text {path }}\left(T_{0}\right)$ and $f_{\text {alt }}\left(T_{0}\right)$, indicating how the marginal disutilities of travel time changes with the baseline travel time $\left(T_{0}\right)$. Several forms of these functions were tested, including piecewise linear functions and dummy variables for different baseline travel times. Travelers with long baseline travel times turn out to have lower values of time (in contrast to the studies cited above, which pertained to motorized modes). The effect turns out to be non-linear in the baseline travel time: the only significant effect was that the marginal disutility of travel time was lower for cyclists with baseline travel time over 40 minutes. There is no (significant) corresponding difference between cyclists with baseline travel times of 15 and 30 minutes, or 45 and 60 minutes. The effect is very similar for street cycling, cycle path cycling and time spent on the alternative mode (although it is somewhat stronger for cycle path 
cycling). For this reason, the functions were defined as $f_{m}=\beta_{1}^{m} \theta_{T_{0} \geq 40}$, where $m=$ \{street, path,alt\} and $\theta_{T_{0} \geq 40}$ is a dummy variable indicating if the baseline travel time is 40 minutes or more. The interaction effect between the cost parameter and the baseline travel time was also investigated but was not significant.

Estimation results are found in Table 2. Model 1 is a restricted model without socioeconomic variables or the effect of the baseline travel time on the value of time. After extensive testing of socioeconomic variables and model specifications, the final model 2 was specified. The values of time implied by the two models are similar and can be found in Table 3 .

Table 2: Logit model parameters of experiment 1

\begin{tabular}{|c|c|c|c|c|}
\hline \multirow[b]{2}{*}{ Parameter } & \multicolumn{2}{|l|}{ Model 1} & \multicolumn{2}{|l|}{ Model 2} \\
\hline & $\begin{array}{l}\text { Parameter } \\
\text { value }\end{array}$ & t-test & $\begin{array}{l}\text { Parameter } \\
\text { value }\end{array}$ & t-test \\
\hline$\beta_{0}^{\text {street }}$ (travel time, street) & -0.227 & -21.89 & -0.249 & -22.20 \\
\hline$\beta_{0}^{\text {path }}$ (travel time, bike path) & -0.150 & -16.09 & -0.173 & -17.15 \\
\hline$\beta_{0}^{\text {alt }}$ (travel time, alt. mode) & -0.125 & -16.35 & -0.131 & -15.73 \\
\hline$\beta_{1}^{\text {street }}$ (effect of $T_{0} \geq 40$, street) & - & - & 0.067 & 4.38 \\
\hline$\beta_{1}^{\text {path }}$ (effect of $T_{0} \geq 40$, bike path) & - & - & 0.079 & 5.56 \\
\hline$\beta_{1}^{\text {alt }}$ (effect of $T_{0} \geq 40$, alternative mode) & - & - & 0.062 & 3.12 \\
\hline$\delta$, mean (mode choice constant) & 3.530 & 8.58 & 3.690 & 8.59 \\
\hline$\delta$, std dev & 2.380 & 21.54 & 2.380 & 21.39 \\
\hline$\delta_{\text {age }}$ (mode constant for age $\geq 40$ yrs) & - & - & 0.747 & 3.63 \\
\hline$\alpha_{1}$ (travel cost) & -0.086 & -18.03 & -0.085 & -17.61 \\
\hline$\alpha_{2}$ (effect of income) & - & - & 0.039 & 4.71 \\
\hline Number of draws & 2000 & & 2000 & \\
\hline Number of observations & 6257 & & 6257 & \\
\hline Number of respondents & 710 & & 710 & \\
\hline Log-likelihood: & -2736.076 & & -2695.664 & \\
\hline Likelihood ratio test: & 3201.891 & & 3282.715 & \\
\hline Rho-square: & 0.369 & & 0.378 & \\
\hline Adjusted rho-square: & 0.368 & & 0.376 & \\
\hline
\end{tabular}


Table 3: Values of time implied by model 1 and model 2

\begin{tabular}{|c|c|c|c|c|c|c|c|}
\hline \multirow[t]{3}{*}{ Values of time in EUR/h } & \multirow[t]{3}{*}{ Model 1} & \multicolumn{6}{|c|}{ Model 2} \\
\hline & & \multicolumn{2}{|c|}{$\begin{array}{l}\text { Evaluated at } \\
\text { average sample } \\
\text { income (3 } 100 \\
\text { EUR/month) }\end{array}$} & \multicolumn{2}{|c|}{$\begin{array}{l}\text { Evaluated at } \\
\text { average population } \\
\text { income ( } 2500 \\
\text { EUR/month) }\end{array}$} & \multicolumn{2}{|c|}{$\begin{array}{l}\text { Reweighted wrt. } \\
\text { employment and } \\
\text { trip purpose (see } \\
\text { text) }\end{array}$} \\
\hline & & $T_{0}<40$ & $T_{0} \geq 40$ & $T_{0}<40$ & $T_{0} \geq 40$ & $T_{0}<40$ & $T_{0} \geq 40$ \\
\hline Value of bicycle time on street & 15.9 & 17.6 & 12.9 & 16.4 & 12.0 & 14.3 & 10.5 \\
\hline Value of bicycle time on bike path & 10.5 & 12.2 & 6.7 & 11.4 & 6.2 & 10.0 & 5.4 \\
\hline Value of time on alt. mode & 8.7 & 9.3 & 4.9 & 8.6 & 4.6 & 7.5 & 4.0 \\
\hline
\end{tabular}

The marginal utility of cost decreases with income, which is taken into account in model specification 2. The right and the middle columns of Model 2 in Table 3 shows the values of time for the sample and the population means of income, respectively (3 $100 \mathrm{EUR} / \mathrm{month}$ and 2600 EUR/month). The population refers to cyclists in the entire Stockholm County.

Since the sample contains almost only work trips, the model cannot control for effects of trip purpose or employment status on the value of time. However, it is possible to use results from the Swedish Value of Time study, in which employment status and trip purpose are shown to affect the value of time, to derive at least an indication of the value of time for an average cyclist in the county of Stockholm. According to that study, employed people have $25 \%$ higher value of time ${ }^{6}$ (ceteris paribus), and an additional $25 \%$ higher on commuting trips. Compared to averages for all cycling trips in the county, the share of employed people is 29 percentage points lower and the share of commuting trips is 32 percentage points lower. This means that the value of time in the present study should be multiplied by a factor 0.87 . The resulting values of time are shown in the left-most columns of Table 3.

Gender was not a significant variable, so there is no need to control for the difference in gender composition between the sample and the county average. The finding that the value of time does not differ between men and women is consistent with the Swedish value of time study (Börjesson \& Eliasson, 2011).

The estimated values of cycling time on street are similar to the results of Wardman et al. (2007). They are also similar to the (implicit) values of time in the national transport model SAMPERS, which lie in the interval 10-20 EUR/h, depending on trip length and gender. Interestingly, the SAMPERS model indicates that the value of time is higher for women and longer trip distances, in contrast to what is found in the present study. The reason for the contrasting results is likely to be self-selection. The SAMPERS model is estimated on a sample representing the entire Swedish population, not just cyclists. This strengthens the hypothesis that the lower value of time for cyclists with long distances in our sample (comprising only cyclists) is due to self-selection.

\footnotetext{
${ }^{6}$ This is the figure for local and regional rail travellers, which is the most relevant comparison.
} 
Cycling on a separated bicycle path instead of on a street with mixed traffic is valued to 5.4 EUR/h (according to model 2, evaluated at average sample income and baseline travel time below 40 minutes). Investment costs for bicycle paths vary widely, but a typical value could be 0.6 MEUR per km (City of Stockholm, 2002), (Hopkinson \& Wardman, 1996). With typical assumptions ${ }^{7}$, this implies that bicycle paths are socially profitable already at yearly average cycling volumes of a little less than 300 cyclists per day, which in urban contexts is very low. Major bicycle paths can easily have 3000 cyclists per day, which would give an incredible benefit/cost ratio of around 13. Note, however, that this is excluding the opportunity cost value of land, which in urban contexts can be a considerable cost.

The fact that a long baseline travel time decreases the marginal disutility of time on both modes, and the fact that this effect contrasts with earlier findings for motorized travel modes, indicate that it is due to a self-selection effect specific for cycling (or slow modes). It is possible that in the segment of travelers with travel time 40 minutes and above, the propensity to cycle decreases with increasing resource value of time (because cycling is relatively slow on longer distances). In the segment of travelers with shorter distances the effect could be weaker or even work in the opposite direction, such that the propensity to cycle increases with the resource values of time (because cycling is relatively fast on short distances).

The self-selection interpretation is plausible for several reasons: a) the competitiveness of cycling in terms of speed declines with distance b) long cycling distances are more likely to require a shower at the destination, increasing the effective total travel time compared to other modes further, c) it is likely that travelers have a lower propensity to cycle if they have a specific appointment or time constraint at the destination, which is also likely to increase the value of travel time. Note that the lower value of time for cyclists with long distances could have structural causes, implying that long distance cyclists always have a lower resource value of time than short distance cyclists. Another possibility is that travelers with long distances only choose to cycle at occasions when they are not in a hurry, have time constraints, or have an out of office appointment.

The value of cycling time is considerably higher than the value of time on the alternative mode: street cycling time savings are valued almost twice as high as time savings on the alternative mode. A similar result was obtained by Wardman et al., where cycling time was valued about three times as much as time savings on the alternative mode. This is in line with the expectation that the direct utility of cycling is lower than for alternative modes, noted in the theory section. The value of time on the alternative mode, averaged over travelers with long and short baseline cycling times, is similar to the value obtained in the Swedish Value of Time study (Börjesson \& Eliasson, 2011), which is $6.8 \mathrm{EUR} / \mathrm{h}$ (for work trips with rail transit, which is the most relevant comparison for the present sample; bus values are lower and car values are higher). That the value of time on the alternative mode is similar to the average value of time for actual public transport users is interesting and non-trivial: it indicates that the difference in value of time between bicyclists and travellers with other modes is mainly due to differences in direct utility,

\footnotetext{
${ }^{7} 40$ years investment lifespan, 4\% discounting rate, $1 \%$ yearly traffic growth, average cycling speed $14.5 \mathrm{~km} / \mathrm{h}$, conversion factor from producer to consumer prices 1.21 .
} 
and that the self-selection effect due to differences in resource value of time is comparatively small.

Various other specifications and hypotheses were explored. The results of sensitivity tests and hypothesis testing that are not discussed above are summarized below.

- The marginal utility of time is not affected by income, only the marginal utility of income.

- Neither of the marginal utility of time, the marginal utility of cost or the mode choice constant differ significantly between genders.

- Only $17 \%$ of the respondents choose bicycle in all 9 choices. Values of time do not change if these respondents are excluded from the estimation sample.

- Neither the value of time on the alternative mode, nor the mode choice constant, depend (significantly) on whether respondents had transit or car as their second-best mode.

- Neither the value of time on the alternative mode, nor the mode choice constant, is affected by whether it rained when the survey was carried out.

- The value of time does not change significantly if non-work trips are excluded from the estimation sample.

- The marginal utilities of time and money do not depend significantly on age. The mode choice constant is lower for younger cyclists. A possible reason for this is that older cyclists value the exercise from cycling higher.

- Respondents who state that exercise is the most important reason for them to choose bicycle do not value of cycling time savings lower than other respondents. Nor do they have a significantly different mode choice constant.

\subsection{Experiment 2: The value of intersections and bicycle parking}

The second experiment was framed as a choice between two alternative bicycle routes which differed in terms of travel time, bicycle parking facilities at the destination, and the number of signalized intersections where the bicyclists had to stop and wait. A logit model with the following utility function was used:

$$
V=\beta_{0} t+\beta_{1} t_{\text {wait }}+\beta_{s} s+\beta_{\text {park }}
$$

Here, $t$ is travel time, $t_{\text {wait }}$ is the total waiting time at signalized intersections, $s$ the number of such intersections and $\beta_{\text {park }}$ a dummy parameter set to zero if there is no bicycle parking facility at the destination. Initially a mixed logit model was estimated, to take into account the correlation of observations from the same individual, specified as:

$$
\Delta V+\varepsilon_{\text {in }}+\delta_{n} \geq=0
$$

The error term $\varepsilon$ was taken to be iid standard logistic and $\delta$ was normally distributed, with a mean and a standard deviation. However, both the mean and the standard deviation of $\delta_{n}$ were highly insignificant, with $t$-statistics of 0.87 (mean) and 0.01 (standard deviation). This is in fact reassuring, and implies that the respondents have no preferences to choose the left or the right hand side alternative, or that this preference is correlated within individuals. For 
this reason, the $\delta_{n}$ was taken out of the final model, resulting in a multinomial logit (MNL) model. Taking out $\delta_{n}$ of the model had no effect on the implied valuations. The parameters of the MNL model are shown in Table 5.

Table 4: Model parameters of experiment 2

\begin{tabular}{|c|c|c|}
\hline Parameter & $\begin{array}{l}\text { Parameter } \\
\text { value }\end{array}$ & $t$-test \\
\hline$\alpha_{5}$ (time) & -0.203 & -32.4 \\
\hline$\alpha_{6}$ (waiting time) & -0.219 & -15.4 \\
\hline$\theta_{1}$ (number of signals) & -0.208 & -19.3 \\
\hline$\theta_{2}$ (bicycle parking) & 0.752 & 21.3 \\
\hline Number of observations: & 6614 & \\
\hline Log-likelihood: & -3565.2 & \\
\hline Likelihood ratio test: & 2038.5 & \\
\hline Rho-square: & 0.222 & \\
\hline Adjusted rho-square: & 0.221 & \\
\hline
\end{tabular}

Table 5: Valuation of experiment 2, in terms of journey bicycling minutes and in monetary terms in EUR

\begin{tabular}{|l|l|l|}
\hline Value of bicycle parking & 3.7 cycling minutes & 0.98 EUR \\
\hline Value of waiting time at intersections & 2.0 cycling minutes & 0.53 EUR \\
\hline $\begin{array}{l}\text { Value of one signaled intersection, in } \\
\text { addition to the delay }\end{array}$ & 1.1 cycling minutes & 0.29 EUR \\
\hline
\end{tabular}

Since there was no travel cost in the second experiment, Table 6 shows intersections and parking facilities valued in terms of bicycling minutes. In the second column of Table 6 , these values are converted into monetary terms using the values of time estimated in experiment 1. Since $90 \%$ of the respondents had access to a separated bicycle path on more than half of the trip we have used the values of time for cycling on a separate bicycle path when converting the values in Table 6.

None of the models (experiment 1 or experiment 2) include randomly distributed travel time or travel cost parameters, although normally and lognormally distributed cost parameters were explored in the estimation process. For the normal distributions, the resulting valuations were approximately the same as in the standard logit model. When estimating lognormal random parameters, valuations increased considerably (due to the fat tail of this distribution). Models were also estimated with non-linear transformations of the time parameters, including Box-Cox transformations, but this gave no significant results.

The fundamental problem encountered when trying to estimate mixed logit models on this data set is that one tries to uncover distributions which may not be fully supported by the data. In fact, we may only identify the distributions of the random parameters within the range of trade-off points implicit in the choice situations we present to the respondents. Because the data do not reveal the entire distribution of the parameters we estimate (in particular, the far right tail of the distribution is unobserved), estimating random parameters means that we 
make (implicit) assumptions about unobserved parts of the distribution. Fosgerau (2006) shows how sensitive the estimated mean value of time is to assumptions about the shape of the distribution when the far right tail of the distribution is unobserved. This fundamental problem is not unique for this data set and cannot be solved here.

\section{Additional benefits}

Improvements for cyclists are often motivated by indirect benefits in the form of increased health and reduced car traffic (causing reductions of emissions, congestion etc.) For example, Sælensminde (2004) argues that such additional benefits constitute a major benefit in bicycle CBA. Additional health effects are also of great importance in (suggested or official) CBA practice in Nordic countries ((Krag, 2005);(Saari \& Metsäranta, 2005);(Swedish Environmental Protection Agency, 2005)).

However, the size of additional health benefits in a CBA will not only depend on the health benefits but also on the extent to which people take health effects into consideration when choosing whether to cycle. As to additional benefits due to reductions of car traffic, these will depend on the cycle/car cross-elasticity and to what extent negative externalities from car traffic are internalized through e.g. fuel taxes. This section tries to assess the magnitude of these factors.

\subsection{Health benefits}

Cycling has significant health effects, e.g. in the form of reduced risk for cardiovascular diseases, especially for groups with low or moderate levels of other exercise. If improvements of cycling possibilities increase the number of cyclists, beneficial health effects will most likely be achieved. Whether these health effects should be added to the CBA, however, depends on the extent that they are already factored in when people make their decision concerning how much to cycle. If, hypothetically, travelers do consider the health effects they will get from cycling and make an accurate judgment of them, then the health benefits will turn up as part of the consumer surplus - both as increased demand for cycling and as a lower value of cycling time - compared to a situation where travelers do not consider health effects. Adding health benefits to a CBA if cyclists already factor in the health effects they are getting will hence be double-counting. To what extent additional health benefits should be included in bicycle CBAs depends on four things: the extent to which cyclists get health benefits out of their cycling; the extent to which bicycle improvements increase cycling ${ }^{8}$; substitution between cycling and other forms of exercise; and the extent to which cyclists take health effects into account when making their travel decisions. We will examine each of these issues in turn.

First, we can note that cycling is an important exercise form for cyclists. For most respondents, cycling is their primary form of exercise: more than $60 \%$ of cyclists exercise less than 2 hours per week apart from cycling. Moreover, our data support the expectation that better cycling possibilities increase cycling. Cyclists are not (only) die-hard cyclists that choose the bicycle

\footnotetext{
${ }^{8}$ Ideally by getting more people to start cycling, i.e. not primarily by making current cyclists cycle more.
} 
no matter what; the relative differences in travel costs and times between bicycle and alternative modes affect their choice. As noted above, the relatively moderate changes of travel times and costs in the choice experiment made $83 \%$ of cyclists choose the alternative mode at least once. One can reasonably assume that this argument works both ways, such that better cycling possibilities will entice some travelers to switch from other modes, and hence potentially lead to health benefits.

However, additional health benefits from increased cycling may to some extent be reduced by the fact that cycling is a substitute for other forms of exercise. Moreover, cyclists exercising more than four hours a week in addition to cycling get considerably less additional health effects out of their cycling. We can estimate the magnitude of these effects by noting that around $60 \%$ of the cyclists state that they would exercise more if they cycled less, or that they already exercise considerably in other forms (more than 4 hours a week). Older cyclists are overrepresented in this group, and since they are the ones who get the most health benefits out of cycling, the total potential health benefit is reduced by up to $60 \%$, depending on the rate of substitution between cycling and other forms of exercise.

The most difficult question is to what extent health benefits are internalized, i.e. to what extent travelers take health benefits from cycling correctly into account when making their travel choices. To shed some light on this, we can note that $52 \%$ of the cyclists state that exercise is the most important reason to choose bicycle. The share increases to $61 \%$ for older cyclists (over 50 years of age). Clearly, a majority of cyclists take health benefits into account, although they may over- or underestimate these health benefits. Obviously, other cyclists may also consider health effects when choosing mode, even if exercise was not their most important reason. If there is a difference between the two groups regarding the extent to which they consider health effects, this should show up in the estimations as a lower value of bicycle time for the group that quote exercise as the most important reason to cycle. But as mentioned above, this is not the case: the values of bicycle time of the groups are not significantly different. Hence, there is no evidence that the group stating other reasons than exercise as the primary reason for cycling disregards the health effects.

Summing up, we can draw the following conclusions from our material:

- Improvements for cyclists tend to increase cycling, and since most cyclists exercise moderately in other forms, there are potential health benefits of cycling improvements.

- To a considerable extent, however, these health benefits are reduced through substitution effects between cycling and other forms exercise. This is particularly pronounced for older cyclists, for which health effects are greater.

- It is virtually impossible to know whether cyclists make a correct assessment of the health effects of cycling, and take this into account when making travel choices. But our results give us no reason to believe that cyclists are unaware of these benefits. On the contrary, the high share of cyclists stating exercise as the primary reason for cycling, and the fact that values of time do not differ between this group and cyclists stating other primary reasons, point to the conclusion that cyclists are indeed well aware of the beneficial effects of cycling. 
That cyclists are "aware" of the health benefits does not necessarily mean that they are able to make an accurate judgment of them. On the contrary, this seems highly unlikely: both under- and overestimations are likely to occur.

Available evidence is far from conclusive, and it probably never will be - but the evidence we have indicates that health effects are indeed factored in when travelers make their decisions, and hence, health effects should not be included in the CBA, at least not entirely.

\subsection{Benefits from reduced car traffic}

At least in public debate, bicycle improvements are often motivated by the need to reduce car traffic. There seem to be great expectations that improving cycling possibilities will entice car drivers to change to bicycle, thereby reducing congestion, emissions, noise etc. Reductions of external costs from car travel should be added to bicycle CBA. On the other hand, a significant share of such external costs is internalized through e.g. fuel taxes, and it is only the external part (i.e. the "non-internalized" share) that should be added to the CBA ${ }^{9}$. Outside congested urban areas, external costs of private car traffic such as noise, emissions, accidents and road maintenance are almost entirely internalized through fuel taxes in Sweden (SIKA, 2006). Hence, the potential social benefits of reducing car traffic by cycle improvements are smaller than sometimes expected.

Also the cross-elasticity between car and bicycle determines the external benefits of cycle improvements. From our material, this cannot be estimated directly, but it is obvious that it cannot be large from one observation: the share of bicyclists quoting car as their second-best travel alternative is a mere $13 \%$. This is consistent with several other studies that have shown that the cross-elasticity between public transit and bicycle is considerably higher than that between car and bicycle.

In summary, we conclude that bicycle improvements will most likely generate very limited social benefits from reduced car traffic. First, even if all "new" cyclists come from existing trips and merely switch mode, we should expect that only $10-15 \%$ of them change from car. Second, only the non-internalized part of external costs from traffic should be included in a CBA, and except for congestion, the internalization rate is high.

These conclusions apply to our specific context, of course. First, Stockholm has good supply of public transit and a high transit share, especially in the central parts, and this increases the share of people having transit as their second-best mode. Second, the rate of internalization of external effects from car traffic varies widely between countries.

\footnotetext{
${ }^{9}$ In Swedish CBA practice, this is handled by presenting the total changes in external costs (emissions etc.) in the $\mathrm{CBA}$, and then adding changes in fuel taxes to the CBA as well. In this way, only the non-internalized parts of the external costs remain in the CBA. Other countries may have other practices.
} 


\section{Conclusions}

The bicycle is often an extremely efficient mode of transport in several respects - travel time, travel cost and space efficiency - and the seemingly growing interest in promoting the possibilities of cycling is promising. It is likely that there are many cost-efficient investments and other measures that will be discovered once traffic planners start to look more closely.

To identify the most cost-efficient improvements applying CBA, values of time are needed. Computing values of time for cycling is the main purpose of this study. The estimated values of time are fairly high, although not extremely high. Interestingly, values of time on the secondbest mode (mostly public transit) coincide with values of time estimated for this mode in independent studies (after correcting for a slightly higher income). This supports the hypothesis that the reason for the higher value of saving cycling time is simply that cycling is more onerous than other modes. The estimated values of time are not representative for the average Swedish cyclist, however; work trips are overrepresented, incomes are slightly higher than average, and the Stockholm traffic situation differs from the rest of Sweden (higher congestion and better public transit). From the high values of time it may be concluded that investments and other measures that reduce cycling times may potentially be very socially profitable. The high willingness to pay for separated bicycle paths compared to street cycling suggests that cycling paths may be very socially profitable.

Our impression is that cycling improvements are often motivated by secondary effects, such as health benefits and reduced car traffic. Our results do not support the notion that such effects constitute a major part of social benefits arising from cycling investments. Regarding health effects, they may be very significant - but our data suggest that these effects are internalized to a large extent, i.e. cyclists take a large share of them into account when making their travel choices. Adding health benefits to the CBA would hence be double-counting. Admittedly, it is extremely difficult to know whether cyclists estimate effects on their health correctly, even if they are "aware" of the effect in principle: both over- and underestimations are possible. Regarding car traffic reductions, it depends on the car/bicycle cross-elasticity and the fraction of external costs that are internalized. Both of these factors will vary between contexts, but from our study, the conclusion is that benefits from reduced car traffic will be very small.

Hence, the expectations that cycling improvements will yield large health or environmental arguments seem exaggerated. But on the other hand, there is no need to retort to "secondary effects"-argument to motivate cycling investments. The bicycle is in many contexts and circumstances an extremely efficient mode of transport - cheap, fast, reliable and requires little space or physical investments. As we have seen, the value of cycling time savings is potentially very high. In our opinion, the bicycle deserves to be viewed as an important and efficient mode of transport - rather than simply a means to obtain other effects.

\section{Acknowledgments}

This research was supported by the National Road Administration and VINNOVA. Pia Sundbergh (WSP Analysis \& Strategy) helped with administering the survey and Karin 
Brundell-Freij (also WSP) provided valuable advice. We are grateful to Lars Hultkrantz for pointing out the relation to the literature on "sin taxes".

\section{References}

Abrantes, P. A. L., \& Wardman, M. R. (2011). Meta-analysis of UK values of travel time: An update. Transportation Research A, 45(1), 1-17.

Becker, G. S. (1965). A Theory of the Allocation of Time. The Economic Journal, 75(299), 493-517.

Börjesson, M., \& Eliasson, J. (forthcoming). The benefits of cycling: Viewing cyclists as travellers rather than non-motorists. John Parkin (ed.): Cycling and sustainability. Emerald.

Börjesson, M., \& Eliasson, J. (2011). Experiences from the Swedish Value of Time study. CTS Working Paper. Centre for Transport Studies, Royal Institute of Technology.

Börjesson, M., Fosgerau, M., \& Algers, S. (2012a). On the income elasticity of the value of travel time. Transportation Research A, 46(2), 368-377.

Börjesson, M., Fosgerau, M., \& Algers, S. (2012b). Catching the tail: Empirical identification of the distribution of the value of travel time. Transportation Research A, 46(2), 378391.

City of Stockholm. (2002). Cykelbanor och cykelfält i Stockholms innerstad. Stockholm Traffic Office Report.

City of Stockholm. (2009). Analys av trafiken i Stockholm - med särskild fokus på effekterna av trängselskatten 2005-2008. Stockholm Traffic Office Report.

DeSerpa, A. C. (1971). A Theory of the Economics of Time. The Economic Journal, 81(324), 828-846.

Ebert, A., \& Carstensen, T. (forthcoming). Cultural development of cycling in Northern Europe. John Parkin (ed.): Cycling and sustainability. Emerald. 
Eliasson, J., \& Lundberg, M. (2011). Do Cost-Benefit Analyses Influence Transport Investment Decisions? Experiences from the Swedish Transport Investment Plan 2010-21. Transport Reviews, 32(1), 29-48.

Elvik, R. (2000). Which are the relevant costs and benefits of road safety measures designed for pedestrians and cyclists? Accident Analysis \& Prevention, 32(1), 37-45.

European Commission. (2007). Towards a new culture for urban mobility.

Evans, A. W. (1972). On the theory of the valuation and allocation and time. Scottish Journal of Political Economy, 19(1), 1-17.

Fosgerau, M. (2006). Investigating the distribution of the value of travel time savings. Transportation Research B, 40(8), 688-707.

Hopkinson, P., \& Wardman, M. (1996). Evaluating the demand for new cycle facilities. Transport Policy, 3(4), 241-249.

Jara-Díaz, S. R. (2003). On the goods-activities technical relations in the time allocation theory. Transportation, 30(3), 245-260.

Jara-Diaz, S. R., \& Guevara, S. R. (2003). Behind the Subjective Value of Travel Time Savings. Journal of Transport Economics and Policy, 37, 29-46.

Katz, R. (1995). Modelling bicycle demands as a main stream transportation planning function. Transportation Research Record, 1502, 22-28.

Krag, T. (2005). Cost benefit Analysis of Cycling, Denmark. Lind (ed): CBA of cycling, TemaNord (Vol. 2005:556). Copenhagen: Nordic Council of Ministers.

O’Donoghue, T., \& Rabin, M. (2003). Studying Optimal Paternalism, Illustrated by a Model of Sin Taxes. American Economic Review, 93(2), 186-191.

O’Donoghue, T., \& Rabin, M. (2006). Optimal sin taxes. Journal of Public Economics, 90(10-11), 1825-1849. 
Ortúzar, J. de D., Iacobelli, A., \& Valeze, C. (2000). Estimating demand for a cycle-way network. Transportation Research A, 34(5), 353-373.

Rietveld, P., \& Daniel, V. (2004). Determinants of bicycle use: do municipal policies matter? Transportation Research A, 38(7), 531-550.

Saari, R., \& Metsäranta, H. (2005). Finnish guidelines for the assessment of walking and cycling projects. Lind (ed): CBA of cycling, TemaNord (Vol. 2005:556). Copenhagen: Nordic Council of Ministers.

Saelensminde, K. (2004). Cost-benefit analyses of walking and cycling track networks taking into account insecurity, health effects and external costs of motorized traffic.

Transportation Research A, 38(8), 593-606.

SIKA. (2006). Vägtrafikens externa effekter 2005 (External costs of road traffic). SIKA report.

Stangeby, I. (1997). Attitudes towards walking and cycling instead of using a car ( No. 370/1997). TÖI Report. Oslo.

Swedish Environmental Protection Agency. (2005). Den samhällsekonomiska nyttan av cykeltrafikåtgärder (The social benefit of cycling measures) ( No. 5456). Naturvårdsverket Rapport. Stockholm.

Wardman, M., Tight, M., \& Page, M. (2007). Factors influencing the propensity to cycle to work. Transportation Research A, 41(4), 339-350. 